\title{
Treatment with Peanut Sprout Root Extract Alleviates Inflammation in a Lipopolysaccharide-Stimulated Mouse Macrophage Cell Line by Inhibiting the MAPK Signaling Pathway
}

\author{
Yun Mi Lee, Eunjung Son and Dong-Seon Kim * \\ Herbal Medicine Research Division, Korea Institute of Oriental Medicine, 1672 Yuseong-daero, Yuseong-gu, \\ Daejeon 34054, Korea; candykong@kiom.re.kr (Y.M.L.); ejson@kiom.re.kr (E.S.) \\ * Correspondence: dskim@kiom.re.kr; Tel.: +82-42-868-9639
}

Received: 29 October 2019; Accepted: 22 November 2019; Published: 25 November 2019

\begin{abstract}
Inflammation is a key response of the immune system to infection but aberrant inflammatory activity can lead to tissue damage and inflammatory diseases. Increasing evidence suggests that peanut sprout root extract (PSRE) has anti-inflammatory activity, and the aim of this study is therefore to investigate the effects of PSRE on the inflammatory response and the molecular mechanisms underpinning this effect in lipopolysaccharide (LPS)-stimulated RAW264.7 cells. Using a combination of cell viability, ELISA, and nitric oxide (NO) assays, together with Western blotting, we showed that PSRE effectively inhibited NO production in LPS-stimulated cells and significantly reduced the expression of pro-inflammatory cytokines, including IL-6, IL-1 $\beta$, and PGE2, at a dose of $200 \mu \mathrm{g} / \mathrm{mL}$ of PSRE, whereas TNF- $\alpha$ expression tended to decrease under PSRE treatment. We also confirmed a dose-dependent and significant inhibition of iNOS and COX-2 protein expression. In addition, PSRE treatment induced anti-inflammatory effects by inhibiting the phosphorylation of MAPKs (ERK, JNK, and $\mathrm{p} 38$ ) and NF-KB activation. Our results indicate that the anti-inflammatory properties of PSRE may result from inhibition of the MAPK pathways, which are known promoters of cytokine secretion.
\end{abstract}

Keywords: peanut sprouts root extract; inflammatory response; MAPK phosphorylation

\section{Introduction}

Inflammation is a local response of the immune system to pathogens and damaged cells and is a vital defense mechanism [1]. However, an excessive or aberrant inflammatory response can be a major contributor to the pathophysiology of acute and chronic human diseases [2]. Macrophages play an important role in the inflammatory response and are naturally activated by exposure to bacterial lipopolysaccharide (LPS), which increases their capacity for phagocytosis during the removal of infectious agents. Activated macrophages overexpress several mediators of inflammation in response to LPS-induced cell injury, such as tumor necrosis factor- $\alpha$ (TNF- $\alpha$ ), interleukin- $1 \beta$ (IL-1 $\beta$ ), interleukin-6 (IL-6), prostaglandin E2 (PGE2), nitric oxide (NO), inducible nitric oxide synthase (iNOS), and cyclooxygenase (COX)-2 [3-5]. Members of the mitogen-activated protein kinase (MAPK) and nuclear factor-kappa B (NF-KB) signaling pathways have been shown to control the mechanisms of the inflammatory response in LPS-stimulated macrophages. The anti-inflammatory effects of suppressing cytokine production by inhibiting MAPK signaling and NF- $\mathrm{KB}$ transactivation have been considered targets for therapies aimed at reducing LPS-induced inflammation, and the levels of these cytokines have been frequently used as markers to assess the activity of anti-inflammatory drugs.

Recently, there has been increasing interest in the health benefits of peanut sprouts (PS), which are germinated peanut seeds. Sprouted peanuts have a lower amount of fats and contain higher amounts 
of carbohydrates, amino acids, and minerals compared to the seed. They also contain a wide variety of phenolic compounds, including a high content of resveratrol, protocatechuic acid, gallic acid, and caffeic acid [6]. Previous studies using PS extract have reported its regulatory effects in the context of cisplatin-induced ototoxicity, obesity, and the inflammatory response in mouse skin and compound 48/80-treated HaCaT keratinocytes [7-9]. However, the activity of LPS-stimulated macrophages anti-inflammatory effects generated by PS extract still remain unknown. We therefore examined the anti-inflammatory effects of PS root extract (PSRE) in LPS-stimulated RAW264.7 macrophage cells.

\section{Results}

\subsection{Chemical Profile of PSRE}

Several published studies using PS extracts have analyzed their chemical composition and described a wide range of compounds, the levels of which vary over the course of germination. We therefore began our investigations by examining the chemical profile of the PSRE generated in this study. Based on the absorption profile and retention time, cichoric acid was identified as a marker compound of peanut sprout roots germinated for 9 days, with day 9 PSRE containing $0.998 \pm 0.011$ $\mathrm{mg} / \mathrm{g}$ of cichoric acid (8.7 min). Day 9 PSRE also contained $0.108 \pm 0.009 \mathrm{mg} / \mathrm{g}$ of caffeic acid and 0.011 $\pm 0.000 \mathrm{mg} / \mathrm{g}$ of resveratrol (Figure 1).
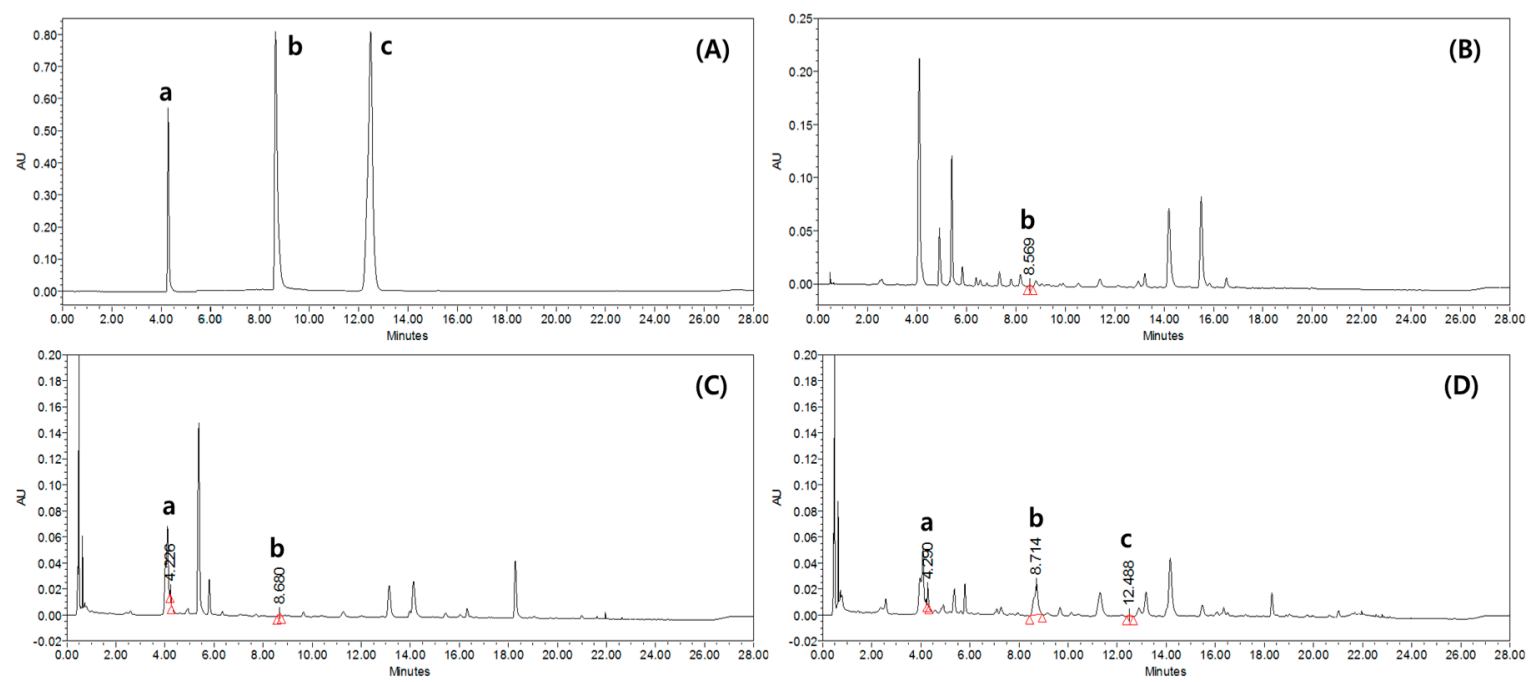

Figure 1. Representative Ultra Performance Liquid Chromatography (UPLC) chromatogram at $320 \mathrm{~nm}$ : (A) standard solutions of caffeic acid (a), cichoric acid (b), and resveratrol (c), (B) day 0 peanut sprout root extract (PSRE), (C) day 3 PSRE, and (D) day 9 PSRE.

\subsection{Effect of PSRE on Viability, NO Production and NF- $\kappa B$ Activation of RAW264.7 Macrophages}

To determine the effect of PSRE treatment on cell viability, NO production and NF- $\mathrm{kB}$ activation during inflammation, RAW264.7 cells were pre-treated with a range of PSRE concentrations, followed by treatment with LPS to induce an inflammatory response. MTT assays showed that treatment with PSRE alone for $24 \mathrm{~h}$ at the maximum concentration of $200 \mu \mathrm{g} / \mathrm{mL}$ produced no significant change in cell viability compared to that in an untreated control group. Therefore, we used concentrations of $200 \mu \mathrm{g} / \mathrm{mL}$ or less for all subsequent experiments (Figure 2A). 
(A)

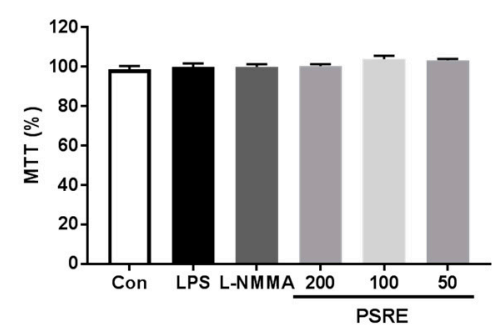

(B)

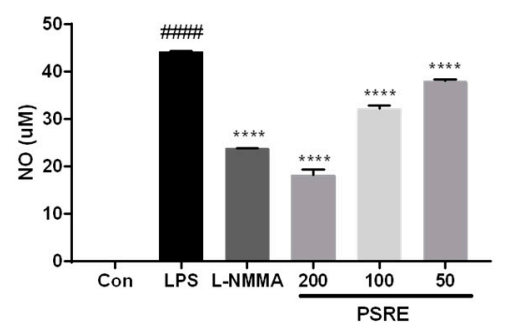

(C)

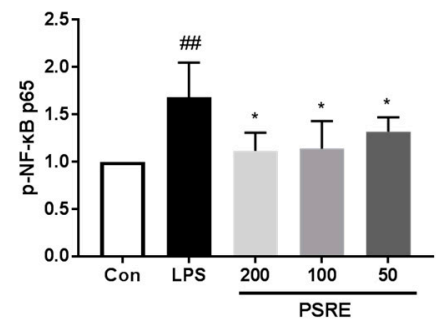

Figure 2. Effect of PSRE on viability, NO production, and NF- $k B$ activation of LPS-induced RAW264.7 macrophages. Cells were pretreated with PSRE $(0,50,100$, or $200 \mu \mathrm{g} / \mathrm{mL})$ for $2 \mathrm{~h}$ and then treated with LPS $(0.5 \mu \mathrm{g} / \mathrm{mL})$ for $22 \mathrm{~h}$. (A) Cell viability was measured using an MTT (3-(4,5-dimethylthiazol-2-yl)-2,5-diphenyltetrazolium bromide) assay. (B) NO production was measured using a Griess reagent assay. L-NG-monomethyl arginine (L-NMMA) was used as a positive control.

(C) NF- $\mathrm{BB}$ activation was measured using an ELISA. Values are expressed as means $\pm \mathrm{SD}(n=3)$.

${ }^{\# \#} p<0.01,{ }^{\# \# \#} p<0.0001$ vs. vehicle control cells. ${ }^{*} p<0.05,{ }^{* * * *} p<0.0001$ vs. LPS-treated cells.

NO is a signaling molecule which plays an important role in the inflammatory response. To examine whether PSRE treatment could modulate NO production, we measured the NO secretion in LPS-induced RAW 264.7 cells after PSRE treatment, using a Griess reagent assay. As shown in Figure 2B, LPS treatment significantly induced NO production compared to that in the untreated control, while cells pretreated with PSRE demonstrated a significant inhibition of NO production in a dose-dependent manner.

Since NF- $k B$ was identified as an important transcription factor that controls several pro-inflammatory mediators, we investigated the activation of NF- $\kappa$ B by ELISA and the results are shown in Figure 2C. PSRE reduced NF- $\kappa$ B levels in a dose dependent manner in LPS-induced RAW 264.7 cells.

\subsection{Effect of PSRE on the Expression of Inflammatory Cytokines in RAW264.7 Macrophages}

To determine whether the ability of PSRE to inhibit inflammatory signaling corresponded to a reduction in the secretion of pro-inflammatory cytokines, we investigated cytokine secretion in LPS-activated macrophages using ELISA. As shown in Figure 3, at a dose of $200 \mu \mathrm{g} / \mathrm{mL}$, PSRE treatment dramatically decreased the expression of the pro-inflammatory cytokines IL-1 $\beta$, IL-6, and PGE2 by $77.7 \%, 63 \%$, and $60 \%$, respectively. TNF- $\alpha$ levels were markedly increased in LPS-treated control cells but pre-treatment with PSRE tended to mitigate this upregulation. 
(A)

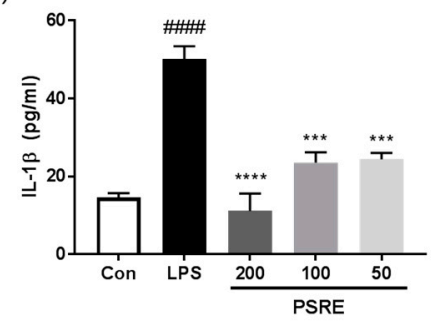

(C)

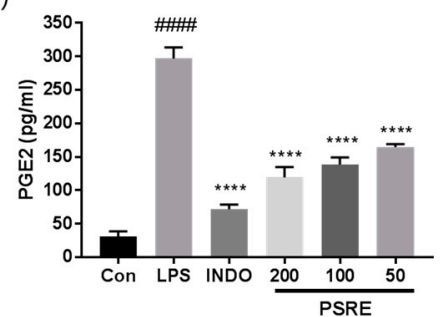

(B)

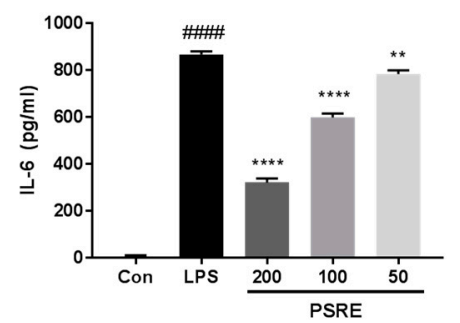

(D)

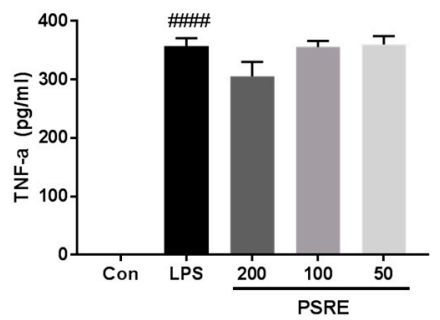

Figure 3. Effect of PSRE on IL-1 $\beta$, IL-6, PGE2, and TNF- $\alpha$ production in LPS-stimulated RAW264.7 macrophages. Cells were pretreated with PSRE $(0,50,100$, or $200 \mu \mathrm{g} / \mathrm{mL})$ for $2 \mathrm{~h}$ and then with LPS $(0.5 \mu \mathrm{g} / \mathrm{mL})$ for $22 \mathrm{~h}$. The supernatants were collected and subjected to ELISA for (A) IL-1 $\beta$, (B) IL-6, (C) PGE2, and (D) TNF- $\alpha$. Indomethacin (INDO), a potent inhibitor of PGE2 synthesis in vitro, was used as a positive control. The values are expressed as the mean $\pm \operatorname{SD}(n=3)$. \#\#\# $p<0.0001$ vs. vehicle control cells. ${ }^{* *} p<0.01 ;^{* * *} p<0.001{ }^{* * * *} p<0.0001$ vs. LPS-treated cells.

\subsection{Effect of PSRE on COX-2 and iNOS Protein Expression}

Two other common mediators of inflammation are COX-2 and iNOS. To evaluate whether PSRE influences COX-2 and iNOS expression, we performed Western blot analysis. LPS-stimulated cells exhibited a significant increase in COX-2 and iNOS expression, when compared to the untreated control. Treatment with PSRE greatly down-regulated the production of COX-2 and iNOS stimulated by LPS in a concentration-dependent manner, as shown in Figure 4. 
(A)

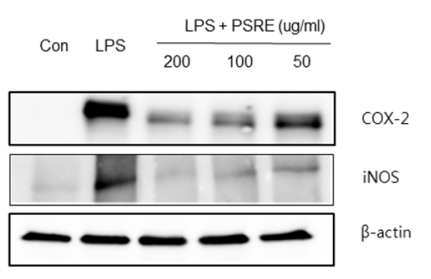

(B)

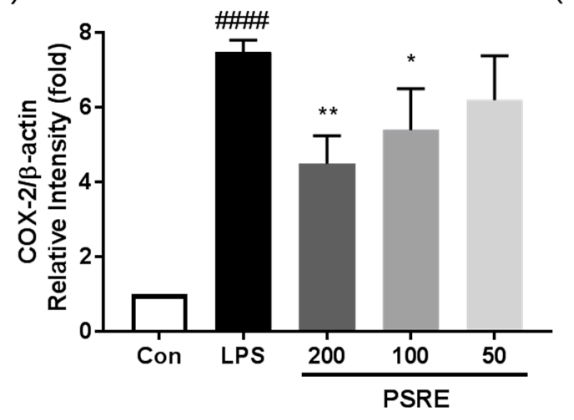

(C)

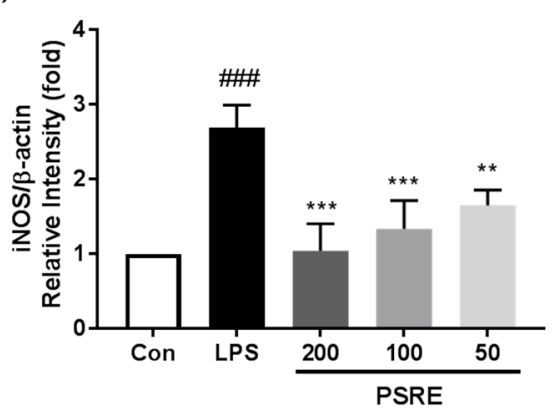

Figure 4. Effect of PSRE on COX-2 and iNOS expression in RAW 264.7 cells. (A) Total protein was extracted and subjected to Western blot analysis. Relative amount of each protein was determined by densitometric analysis. The levels of (B) COX-2 and (C) iNOS were estimated according to the value of each control. The values are expressed as the mean $\pm \operatorname{SD}(n=3) .{ }^{\# \#} p<0.001,{ }^{\# \# \#} p<0.0001$ vs. vehicle control cells. ${ }^{*} p<0.05,{ }^{* *} p<0.01,{ }^{* * *} p<0.001$ vs. LPS-treated cells.

\subsection{Effect of PSRE on MAPK Phosphorylation}

While a number of signaling pathways have been shown to mediate inflammation, one of the most well-known is the MAPK signaling pathway. We therefore used Western blot analysis to determine whether PSRE treatment of activated macrophages affected the phosphorylation of the upstream MAPK kinases, namely p38 MAPK, ERK, and JNK. As shown in Figure 5, LPS treatment elevated the phosphorylation of p38 MAPK, ERK, and JNK. In addition, the phosphorylation of p38 MAPK and ERK was remarkably attenuated by PSRE treatment. These results suggest that PSRE treatment blocks the p38 MAPK, ERK, and JNK pathways to exert its anti-inflammatory effects on LPS-treated RAW 264.7 cells. 
(A)

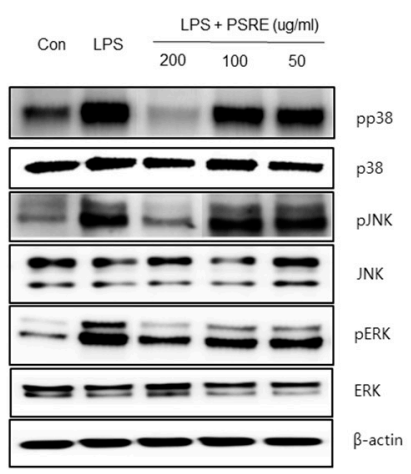

(C)

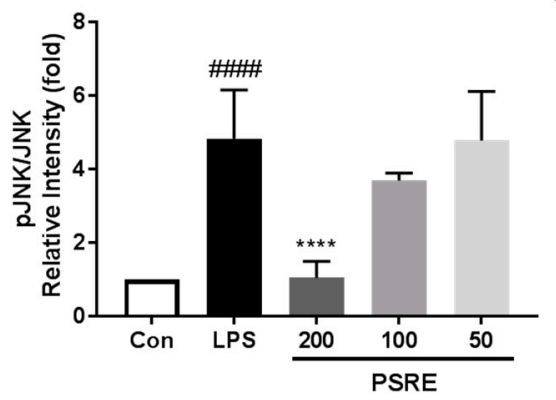

(B)

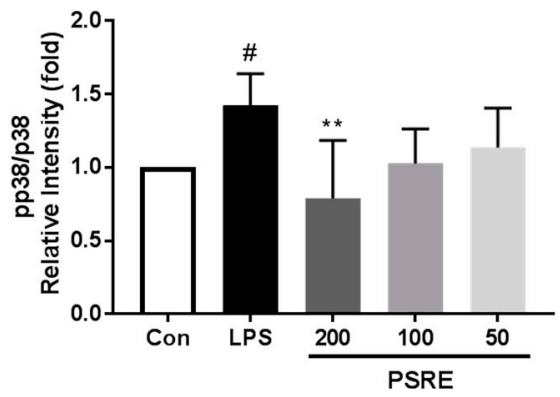

(D)

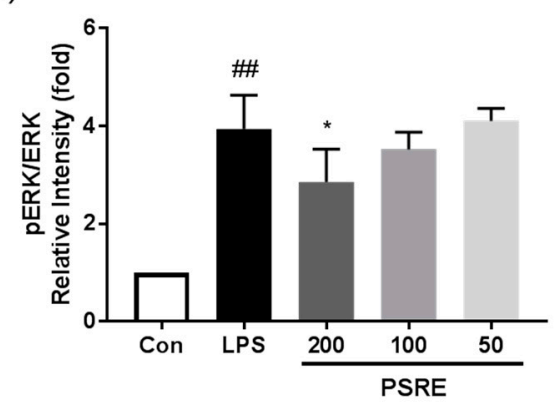

Figure 5. Effect of PSRE on MAPK phosphorylation in RAW 264.7 cells. (A) Total protein was extracted and subjected to Western blot analysis. Relative amount of each protein was determined by densitometric analysis. The levels of (B) p38, (C) JNK, and (D) ERK were estimated according to the value of each control. The values are expressed as the mean $\pm \mathrm{SD}(n=3) .{ }^{\#} p<0.05$, ${ }^{\# \#} p<0.01$, \#\#\#\# $p<0.0001$ vs. vehicle control cells. ${ }^{*} p<0.05,{ }^{* *} p<0.01,{ }^{* * * *} p<0.0001$ vs. LPS-treated cells.

\section{Discussion}

Inflammation plays a pivotal role in the defense response of many organs to pathogenic stimuli, such as bacterial infection [10]. LPS is the immunologically active component of Gram-negative bacterial cell walls and is thus commonly employed as a proxy for infection. LPS stimulates macrophages to induce numerous inflammatory mediators including NO, IL- $1 \beta$, TNF- $\alpha$, PGE2, and cyclooxygenase [11-14]. NO is a vital cellular signaling molecule involved in inflammation through iNOS upregulation, and the over-production of $\mathrm{NO}$ has been linked to various inflammatory disorders [15]. In addition, NO induces PGE2 production, resulting in accelerated inflammatory responses through its activation of COX-2 [16].

Pro-inflammatory cytokines such as TNF- $\alpha$, IL-1 $\beta$, and IL- 6 act as messengers to stimulate the inflammatory process [17]. TNF- $\alpha$ induces synergy in NO production in LPS-stimulated macrophages, causing inflammatory responses such as vasodilatation, edema, and fever [18]. IL-1 $\beta$ is activated by caspase-1, and is critical for the response to infection as it influences the production of NO [19]. In addition, IL-6 is a pro-inflammatory cytokine with many functions, including propagating chronic inflammation and inducing acute inflammation [20]. Therefore, targeting the inflammatory mediators and cytokines is a useful strategy in anti-inflammatory therapy [21]. In the present study, we provided evidence that suppression of NO and PGE2 production by PSRE treatment correlated with a decrease in the expression levels of COX-2 and iNOS. In addition, we also found that PSRE inhibits TNF- $\alpha$, IL-1 $\beta$, and IL-6 production in LPS-stimulated RAW 264.7 cells.

MAPK signaling pathways play an important role in the up-regulation of COX-2, iNOS, and inflammatory cytokines induced by various stimuli [22-24]. Thus, inactivation of MAPKs might inhibit the synthesis of pro-inflammatory cytokines and their signaling. Therefore, we investigated whether the phosphorylation of JNK, ERK, and p38 MAPK was inhibited in LPS-stimulated RAW264.7 
cells. Our data showed that PSRE had remarkable inhibitory effects on LPS-stimulated MAPK phosphorylation at concentrations of $200 \mu \mathrm{g} / \mathrm{mL}$.

The MAPK signaling pathways regulate transcription factors, such as NF- $\mathrm{kB}$, that transcriptionally activate many genes involved in the regulation of immune responses, cell adhesion, and survival [25]. During the inflammatory process, NF- $\mathrm{KB}$ is translocated to the nucleus and transcriptionally activates various inflammatory cytokines such as iNOS, COX-2, TNF- $\alpha$, and IL-1 $\beta[26,27]$. Our data show that PSRE had a significant inhibitory effect on the LPS-stimulated activation of NF- $\kappa$ B. These results suggest that PSRE plays an anti-inflammatory role in LPS-induced macrophage cells. Indeed, our promising in vitro data could form the basis of future studies examining the effect of PSRE in animal models of inflammation-related disease [9].

Research on the health benefits of PS has been gaining increasing prominence, revealing that PS extracts have considerable antioxidant potential. The sprouting process promotes significant changes in bioactive compounds that contain various types of phenolic compounds, many of which are antioxidants [28]. Limmongkon et al. reported that the peanut seed coat, germinated kernel, and germinated root were abundant in a variety of phenolic substances, such as caffeic acid, coumaric acid, hesperidin, transarachidin-1, arahypin 2, arahypin 3, resveratrol, 4-isopentadienyl-3,5,3', $4^{\prime}$-tetrahydroxystilbene (IPP), trans-3' -isopentadienyl-3,5, $4^{\prime}$-trihydroxystilbene (IPD), transarachidin-1, trans-arachidin-2, and trans-arachidin-3 [29].

In our study, cichoric acid was barely detectable in PSRE on day 0 and day 3 , but was detectable at a level of $0.998 \pm 0.011 \mathrm{mg} / \mathrm{g}$ on day 9 of germination. As a result, we speculate that the appearance of cichoric acid may be due to increased levels of a compound that is converted during the germination process. In addition, our analyses revealed the presence of $0.108 \pm 0.009 \mathrm{mg} / \mathrm{g}$ of caffeic acid and $0.011 \pm 0.000 \mathrm{mg} / \mathrm{g}$ of resveratrol in day 9 PSRE. To our knowledge, this is the first paper to confirm the presence of cichoric acid in PSRE. Cichoric acid is a natural phenolic compound obtained in a number of plants, such as chicory (Cichorium intybus) and Echinacea (Echinacea purpurea) and it possesses antioxidant, anti-inflammatory, antiviral, and analgesic activities in vitro and in vivo [30-32]. However, cichoric acid has not been reported to have effects against inflammation in LPS-induced macrophages. Further investigation into the effects of this compound on inflammation in LPS-induced macrophages is therefore required.

\section{Materials and Methods}

\subsection{PSRE Preparation}

Peanut (Arachis hypogaea L.) seeds were washed, incubated in water at $20^{\circ} \mathrm{C}$ for $18 \mathrm{~h}$, and then germinated in a hydroponics system at $80 \%$ humidity at $26^{\circ} \mathrm{C}$ in the dark. After harvesting 3 to 9 days after germination, peanut sprout roots were dried, finely powdered, and extracted with $70 \%$ ethanol for $3 \mathrm{~h}$ at reflux, and these extracts were concentrated under reduced pressure, freeze dried, and stored at $4{ }^{\circ} \mathrm{C}$.

\subsection{Chemical Profiling of PSRE}

A Waters ACQUITY Ultra Performance Liquid Chromatography (UPLC) system equipped with a quaternary pump, auto-sampler, and photodiode array detector with an ACQUITY UPLC ${ }^{\circledR}$ BEH C18, $100 \times 2.1 \mathrm{~mm}, 1.7 \mu \mathrm{m}$ column was used for the analysis (Waters, MA, USA). An elution with solvent A $(0.1 \%$ phosphoric acid) and solvent $B$ (Acetonitrile) in a gradient elution at a flow rate of $0.5 \mathrm{~mL} / \mathrm{min}$ was carried out as follows: 0-2 min, 5-5\% B; 2-4 min, 5-8\% B; 4-20 min, 8-26\% B; $20-24 \mathrm{~min}, 26-100 \%$ B; 24-26 min, 100-5\% B; 26-min, 5-5\% B. The detection wavelength was set at $320 \mathrm{~nm}$. The column temperature was kept at $40^{\circ} \mathrm{C}$ and the injection volume was $2 \mu \mathrm{L}$. 


\subsection{Cell Culture}

The murine macrophage RAW264.7 cell line, purchased from American Type Culture Collection, was cultured in Dulbecco's Modified Eagle's medium (DMEM), supplemented with $10 \%$ heat inactivated fetal bovine serum (FBS), $1 \%$ penicillin $(100 \mathrm{IU} / \mathrm{mL})$ at $5 \% \mathrm{CO}_{2}$ and $37^{\circ} \mathrm{C}$. The medium was replaced with serum-free DMEM medium. PSRE (50, 100, and $200 \mu \mathrm{g} / \mathrm{mL}$ ) was dissolved in 100\% DMSO, and each concentration was diluted to a final DMSO content of $0.1 \%$ when used to treat cells for $2 \mathrm{~h}$. The control groups were treated with vehicle solution. LPS $(0.5 \mu \mathrm{g} / \mathrm{mL}$ Sigma-Aldrich Chemical Co., St. Louis, MO, USA) was added in the presence or absence of PSRE for an additional $22 \mathrm{~h}$ to stimulate the cells.

\subsection{Cell Viability}

Cell viability assays were performed to determine the cytotoxicity of PSRE using 3-(4,5-dimethylthiazol-2-yl)-2,5-diphenyltetrazolium bromide (MTT) (Sigma-Aldrich Chemical Co., St. Louis, MO, USA). RAW 264.7 cells were incubated with various concentrations of PSRE $(0-200 \mu \mathrm{g} / \mathrm{mL})$ for $24 \mathrm{~h}$ and the treatment medium then completely replaced with MTT solution. MTT was dissolved in serum-free DMEM at concentration of $0.5 \mathrm{mg} / \mathrm{mL}$, and $100 \mu \mathrm{L}$ of this solution was added to cell cultures for $4 \mathrm{~h}$ in 96 -well culture plates. The plates were removed from the incubator and the formazan crystals were dissolved by the addition of $100 \mu \mathrm{L}$ of dimethyl sulfoxide. The absorbance at $570 \mathrm{~nm}$ was read on a microplate reader (Bio-Rad, Hercules, CA, USA) as a measure of cell viability. The absorbance was normalized to that of cells incubated in the control medium, and these cells were considered $100 \%$ viable. The percentage of cell viability was calculated as follows: (Mean optical density (OD) in PSRE-treated cells/Mean OD in untreated cells $\times 100$ ).

\subsection{NO and Inflammatory Cytokine Assays}

NO production was analyzed using the Griess Reagent System, according to the manufacturer's instructions (Promega, Madison, WI, USA). Briefly, the accumulation of nitrite in culture supernatants was detectable via a chemical reaction with the Griess reagents which produces a dye measurable by spectrophotometry. L-NG-monomethyl arginine (L-NMMA) was used as a positive control. Collected cell supernatants were reacted with Griess reagent, and the absorbance was measured at $540 \mathrm{~nm}$. For the measurement of NF- $\mathrm{kB}$ levels, cells were lysed and processed according to the manufacturer's instructions using the Pathscan phospho-p65 (Ser536) ELISA kit (Cell Signaling). The levels of IL-1 $\beta$, IL-6, TNF- $\alpha$, and PGE2 were measured using ELISA kits from R\&D Systems (Minneapolis, MN, USA) according to the manufacturer's protocol. Indomethacin (INDO), a potent inhibitor of PGE2 synthesis in vitro, was used as a positive control.

\subsection{Western Blot Analysis}

Cell lysates were prepared from RAW264.7 cells in 1× Laemmli lysis buffer and boiled for $10 \mathrm{~min}$. The samples $(20 \mathrm{~g})$ were diluted with $1 \times$ lysis buffer, separated by electrophoresis $(4.5 \%$ to $15 \%$ gradient), and transferred onto polyvinylidene fluoride (PVDF) membranes. The membranes were reacted with primary antibodies against COX-2, iNOS, p-p38, p38, pJNK, JNK, pERK, ERK, and $\beta$-actin (1:1000 dilution) (Cell Signaling Technology, Beverly, MA, USA). Specifically, bound horseradish peroxide-conjugated secondary antibodies were detected using an enhanced chemiluminescence detection system (Amersham Bioscience, Buckinghamshire, UK). Protein expression levels were determined by the analysis of the signals captured on the PVDF membrane using an image analyzer (LAS-3000, Fujifilm, Tokyo, Japan).

\subsection{Statistical Analysis}

The results are expressed as the mean \pm standard deviation (SD) and analyzed using one-way analysis of variance (ANOVA) followed by Dunnett's tests for multiple comparisons or unpaired 
Student's t-tests for two-group comparisons. All analyses were performed using Prism 7.0 (GraphPad Software, San Diego, CA, USA), and $p$-values $<0.05$ were considered statistically significant.

\section{Conclusions}

The results of our study show that PSRE treatment suppressed the inflammatory mediator (NO and PGE2) production, likely through decreased expression of iNOS and COX-2, and inhibited inflammatory cytokines such as TNF- $\alpha$, IL-1 $\beta$, and IL- 6 through the inhibition of MAPK signaling and NF- $\mathrm{KB}$ activation in LPS-induced macrophages. These findings suggest that PSRE may be a potential therapeutic agent for the treatment of inflammation-related diseases.

Author Contributions: This work was carried out with collaboration among all authors. Y.M.L. performed the experiments and wrote the manuscript. E.S. performed the experiments, analyzed the data, and reviewed the manuscript. D.-S.K. designed and supervised the study. All authors read and approved the final manuscript.

Funding: This research was supported by grants from the Korea Institute of Oriental Medicine (KSN1911310) and Korea Institute of Planning and Evaluation for Technology in Food, Agriculture, Forestry (IPET) through Technology Commercialization Support Program, funded by Ministry of Agriculture, Food and Rural Affairs (MAFRA) (817036-03).

Acknowledgments: The authors thank all of the colleagues who contributed to this study.

Conflicts of Interest: The authors declare no conflict of interest.

\section{Abbreviations}

$\begin{array}{ll}\text { PSRE } & \text { Peanut Sprouts Root Extract } \\ \text { LPS } & \text { Lipopolysaccharide } \\ \text { NO } & \text { Nitric oxide } \\ \text { TNF- } \alpha & \text { Tumor necrosis factor- } \alpha \\ \text { IL-1 } \beta & \text { Interleukin-1 } \beta \\ \text { IL-6 } & \text { Interleukin-6 } \\ \text { PGE2 } & \text { Prostaglandin E2 } \\ \text { iNOS } & \text { Inducible nitric oxide synthase } \\ \text { COX-2 } & \text { Cyclooxygenase } 2 \\ \text { MAPK } & \text { Mitogen-activated protein kinase } \\ \text { ERK } & \text { Extracellular signal-regulated kinase } \\ \text { JNK } & \text { c-Jun n-terminal kinase }\end{array}$

\section{References}

1. Ye, H.; Wang, Y.; Yan, J.; Jenson, A.B. Characterization of the anti-inflammation mechanism for the AO herbal extract. Exp. Mol. Pathol. 2016, 101, 341-345. [CrossRef] [PubMed]

2. Kim, K.N.; Ko, Y.J.; Kang, M.C.; Yang, H.M.; Roh, S.W.; Oda, T.; Jeon, Y.J.; Jung, W.K.; Heo, S.J.; Yoon, W.J.; et al. Anti-inflammatory effects of trans-1,3-diphenyl-2,3-epoxypropane-1-one mediated by suppression of inflammatory mediators in LPS-stimulated RAW 264.7 macrophages. Food Chem. Toxicol.: Int. J. Publ. Br. Ind. Biol. Res. Assoc. 2013, 53, 371-375. [CrossRef] [PubMed]

3. Koh, T.J.; DiPietro, L.A. Inflammation and wound healing: The role of the macrophage. Expert Rev. Mol. Med. 2011, 13, e23. [CrossRef] [PubMed]

4. Jung, C.H.; Jung, H.; Shin, Y.C.; Park, J.H.; Jun, C.Y.; Kim, H.M.; Yim, H.S.; Shin, M.G.; Bae, H.S.; Kim, S.H.; et al. Eleutherococcus senticosus extract attenuates LPS-induced iNOS expression through the inhibition of Akt and JNK pathways in murine macrophage. J. Ethnopharmacol. 2007, 113, 183-187. [CrossRef] [PubMed]

5. Cho, B.O.; Ryu, H.W.; So, Y.; Lee, C.W.; Jin, C.H.; Yook, H.S.; Jeong, Y.W.; Park, J.C.; Jeong, I.Y. Anti-Inflammatory Effect of Mangostenone F in Lipopolysaccharide-Stimulated RAW264.7 Macrophages by Suppressing NF-kappaB and MAPK Activation. Biomol. Ther. 2014, 22, 288-294. [CrossRef]

6. Wang, K.H.; Lai, Y.H.; Chang, J.C.; Ko, T.F.; Shyu, S.L.; Chiou, R.Y. Germination of peanut kernels to enhance resveratrol biosynthesis and prepare sprouts as a functional vegetable. J. Agric. Food Chem. 2005, 53, 242-246. [CrossRef] 
7. Youn, C.K.; Jo, E.R.; Sim, J.H.; Cho, S.I. Peanut sprout extract attenuates cisplatin-induced ototoxicity by induction of the Akt/Nrf2-mediated redox pathway. Int. J. Pediatric Otorhinolaryngol. 2017, 92, 61-66. [CrossRef]

8. Kang, N.E.; Ha, A.W.; Woo, H.W.; Kim, W.K. Peanut sprouts extract (Arachis hypogaea L.) has anti-obesity effects by controlling the protein expressions of PPARgamma and adiponectin of adipose tissue in rats fed high-fat diet. Nutr. Res. Pract. 2014, 8, 158-164. [CrossRef]

9. Choi, D.I.; Choi, J.Y.; Kim, Y.J.; Lee, J.B.; Kim, S.O.; Shin, H.T.; Lee, S.C. Ethanol Extract of Peanut Sprout Exhibits a Potent Anti-Inflammatory Activity in Both an Oxazolone-Induced Contact Dermatitis Mouse Model and Compound 48/80-Treated HaCaT Cells. Ann. Dermatol. 2015, 27, 142-151. [CrossRef]

10. Guha, M.; Mackman, N. LPS induction of gene expression in human monocytes. Cell. Signal. 2001, 13, 85-94. [CrossRef]

11. Hiraiwa, K.; van Eeden, S.F. Contribution of lung macrophages to the inflammatory responses induced by exposure to air pollutants. Mediat. Inflamm. 2013, 2013, 619523. [CrossRef] [PubMed]

12. Laskin, D.L.; Sunil, V.R.; Gardner, C.R.; Laskin, J.D. Macrophages and tissue injury: Agents of defense or destruction? Annu. Rev. Pharmacol. Toxicol. 2011, 51, 267-288. [CrossRef] [PubMed]

13. McNelis, J.C.; Olefsky, J.M. Macrophages, immunity, and metabolic disease. Immunity 2014, 41, 36-48. [CrossRef] [PubMed]

14. Raetz, C.R.; Whitfield, C. Lipopolysaccharide endotoxins. Annu. Rev. Biochem. 2002, 71, 635-700. [CrossRef] [PubMed]

15. Cho, B.O.; So, Y.; Jin, C.H.; Nam, B.M.; Yee, S.T.; Jeong, I.Y. 3-deoxysilybin exerts anti-inflammatory effects by suppressing NF-kappaB activation in lipopolysaccharide-stimulated RAW264.7 macrophages. Biosci. Biotechnol. Biochem. 2014, 78, 2051-2058. [CrossRef] [PubMed]

16. Lee, J.H.; Ko, J.Y.; Samarakoon, K.; Oh, J.Y.; Heo, S.J.; Kim, C.Y.; Nah, J.W.; Jang, M.K.; Lee, J.S.; Jeon, Y.J. Preparative isolation of sargachromanol E from Sargassum siliquastrum by centrifugal partition chromatography and its anti-inflammatory activity. Food Chem. Toxicol. Int. J. Publ. Br. Ind. Biol. Res. Assoc. 2013, 62, 54-60. [CrossRef] [PubMed]

17. Chen, L.; Deng, H.; Cui, H.; Fang, J.; Zuo, Z.; Deng, J.; Li, Y.; Wang, X.; Zhao, L. Inflammatory responses and inflammation-associated diseases in organs. Oncotarget 2018, 9, 7204-7218. [CrossRef]

18. Zelova, H.; Hosek, J. TNF-alpha signalling and inflammation: Interactions between old acquaintances. Inflamm. Res. Off. J. Eur. Histamine Res. Soc. 2013, 62, 641-651. [CrossRef]

19. Lima-Junior, D.S.; Costa, D.L.; Carregaro, V.; Cunha, L.D.; Silva, A.L.; Mineo, T.W.; Gutierrez, F.R.; Bellio, M.; Bortoluci, K.R.; Flavell, R.A.; et al. Inflammasome-derived IL-1beta production induces nitric oxide-mediated resistance to Leishmania. Nat. Med. 2013, 19, 909-915. [CrossRef]

20. Barnes, T.C.; Anderson, M.E.; Moots, R.J. The many faces of interleukin-6: The role of IL-6 in inflammation, vasculopathy, and fibrosis in systemic sclerosis. Int. J. Rheumatol. 2011, 2011, 721608. [CrossRef]

21. Chen, Y.C.; Shen, S.C.; Lee, W.R.; Hou, W.C.; Yang, L.L.; Lee, T.J. Inhibition of nitric oxide synthase inhibitors and lipopolysaccharide induced inducible NOS and cyclooxygenase-2 gene expressions by rutin, quercetin, and quercetin pentaacetate in RAW 264.7 macrophages. J. Cell. Biochem. 2001, 82, 537-548. [CrossRef] [PubMed]

22. Buapool, D.; Mongkol, N.; Chantimal, J.; Roytrakul, S.; Srisook, E.; Srisook, K. Molecular mechanism of anti-inflammatory activity of Pluchea indica leaves in macrophages RAW 264.7 and its action in animal models ofinflammation. J. Ethnopharmacol. 2013, 146, 495-504. [CrossRef] [PubMed]

23. Chun, J.; Choi, R.J.; Khan, S.; Lee, D.S.; Kim, Y.C.; Nam, Y.J.; Lee, D.U.; Kim, Y.S. Alantolactone suppresses inducible nitric oxide synthase and cyclooxygenase-2 expression by down-regulating NF-kappaB, MAPK and AP-1 via the MyD88 signaling pathway in LPS-activated RAW 264.7 cells. Int. Immunopharmacol. 2012, 14, 375-383. [CrossRef] [PubMed]

24. Yang, Y.; Kim, S.C.; Yu, T.; Yi, Y.S.; Rhee, M.H.; Sung, G.H.; Yoo, B.C.; Cho, J.Y. Functional roles of p38 mitogen-activated protein kinase in macrophage-mediated inflammatory responses. Mediat. Inflamm. 2014, 2014, 352371. [CrossRef]

25. Bonizzi, G.; Karin, M. The two NF-kappaB activation pathways and their role in innate and adaptive immunity. Trends Immunol. 2004, 25, 280-288. [CrossRef]

26. Bose, S.; Kar, N.; Maitra, R.; DiDonato, J.A.; Banerjee, A.K. Temporal activation of NF-kappaB regulates an interferon-independent innate antiviral response against cytoplasmic RNA viruses. Proc. Natl. Acad. Sci. USA 2003, 100, 10890-10895. [CrossRef] 
27. Sohn, K.H.; Jo, M.J.; Cho, W.J.; Lee, J.R.; Cho, I.J.; Kim, S.C.; Kim, Y.W.; Jee, S.Y. Bojesodok-eum, a Herbal Prescription, Ameliorates Acute Inflammation in Association with the Inhibition of NF-kappaB-Mediated Nitric Oxide and ProInflammatory Cytokine Production. Evid. Based Complementary Altern. Med. Ecam 2012, 2012, 457370. [CrossRef]

28. Kim, H.J.; Park, K.J.; Lim, J.H. Metabolomic analysis of phenolic compounds in buckwheat (Fagopyrum esculentum M.) sprouts treated with methyl jasmonate. J. Agric. Food Chem. 2011, 59, 5707-5713. [CrossRef]

29. Limmongkon, A.; Nopprang, P.; Chaikeandee, P.; Somboon, T.; Wongshaya, P.; Pilaisangsuree, V. LC-MS/MS profiles and interrelationships between the anti-inflammatory activity, total phenolic content and antioxidant potential of Kalasin 2 cultivar peanut sprout crude extract. Food Chem. 2018, 239, 569-578. [CrossRef]

30. Tsai, K.L.; Kao, C.L.; Hung, C.H.; Cheng, Y.H.; Lin, H.C.; Chu, P.M. Chicoric acid is a potent anti-atherosclerotic ingredient by anti-oxidant action and anti-inflammation capacity. Oncotarget 2017, 8, 29600-29612. [CrossRef]

31. Ding, H.; Ci, X.; Cheng, H.; Yu, Q.; Li, D. Chicoric acid alleviates lipopolysaccharide-induced acute lung injury in mice through anti-inflammatory and anti-oxidant activities. Int. Immunopharmacol. 2019, 66, 169-176. [CrossRef] [PubMed]

32. Lee, N.Y.; Chung, K.S.; Jin, J.S.; Bang, K.S.; Eom, Y.J.; Hong, C.H.; Nugroho, A.; Park, H.J.; An, H.J. Effect of Chicoric Acid on Mast Cell-Mediated Allergic Inflammation in Vitro and in Vivo. J. Nat. Prod. 2015, 78, 2956-2962. [CrossRef] [PubMed]

(C) 2019 by the authors. Licensee MDPI, Basel, Switzerland. This article is an open access article distributed under the terms and conditions of the Creative Commons Attribution (CC BY) license (http://creativecommons.org/licenses/by/4.0/). 